\title{
BOAVENTURA DE SOUSA SANTOS E A SOCIEDADE CIVIL EM TEMPOS DE GLOBALIZAÇÃO
}

\author{
Boaventura de Souza Santos and the civil \\ society in the globalization time
}

\author{
Eduardo Tadeu Pereira
}

Doutor em Educação pela UNICAMP. Campinas, SP - Brasil, e-mail: profedutadeu@ gmail.com

\begin{abstract}
Resumo
Esse artigo apresenta a concepção que Boaventura de Sousa Santos tem sobre o atual momento vivido, identificado correntemente como o da globalização. Contrapondo-se a essa noção unívoca desse termo, na primeira parte do texto são apresentados os argumentos desse autor para questionar a globalização com a sua noção de "globalizações". Na segunda parte, procura-se aprofundar a noção de Boaventura sobre a globalização como uma opção política, e não como inexorabilidade histórica. Por fim, é destacada a luta pela emancipação como práxis da globalização contra-hegemônica, com vistas a construir alternativas que assegurem a dignidade humana nessa realidade orientada pelos interesses e necessidades do capital.
\end{abstract}

Palavras-chave: Boaventura de Sousa Santos; Globalização; Sociedade civil. 


\begin{abstract}
This article presents the concept that Boaventura de Sousa has about the actual time, identified as the globalization. Opposing the notion of this term, in the first part of the text it is presented the arguments of this author that questions the globalization with its notion of "globalizations". The second part, tries to deepen in the notion of Boaventura about the globalization as a political option, and not as a historical inexorab. In conclusion, it is highlighted the fight for the emancipation as praxis of the cons-hegemonic globalization, with hopes to construct alternatives that assures the human dignity in this reality run by the interest and necessity of the capital.
\end{abstract}

Keywords: Boaventura de Sousa Santos; Globalization; Civil society.

\title{
Sobre a globalização e as globalizações
}

O momento presente tem tido implicações importantes sobre a possibilidade da construção de alternativas democráticas participativas no Estado e na Sociedade Civil. Identificado pela mídia como globalização, para Boaventura de Souza Santos (2001) assistimos a "globalizações".

O termo globalização tem sido usado pelos meios de comunicação de massa, em parte como forma de construção de um senso comum em torno da palavra, como tendo um sentido unívoco, que significaria um movimento inexorável e que incluiria, entre outras coisas, a liberalização do comércio internacional, com a abertura das fronteiras para a entrada de produtos e serviços, certas políticas econômicas, como o controle inflacionário, e também certos padrões de organização política, como a democracia representativa liberal, além de outros ditames sociais e culturais.

Uma das tarefas mais necessárias nesse momento àqueles que não aceitam esse senso comum em relação ao termo globalização é exatamente desfazer tal mito em torno desse conceito, procurando analisar o mundo com maior acuidade e percebendo "as globalizações", como corretamente afirma Boaventura de Sousa Santos: 
A globalização, longe de ser consensual, é [...] um vasto e intenso campo de conflitos entre grupos sociais, Estados e interesses hegemônicos, por um lado, e grupos sociais, Estados e interesses subalternos, por outro; e mesmo no interior do campo hegemônico há divisões mais ou menos significativas. (SANTOS, 2001, p. 33).

Procura o interesse hegemônico fazer crer que desapareceram as clivagens políticas (SANTOS, 2001, p. 33), que é chegado o fim da história, que já não há mais o que fazer, que o rumo do futuro é inexorável, bastando aos países e povos procurarem a melhor forma de se encaixarem nessa nova ordem mundial.

O estatuto da globalização nestes debates é o de freqüentemente ou surgir como uma resposta para todos os tipos de questão levantadas pelas mudanças manifestas e palpáveis experienciadas pelas sociedades ocidentais contemporâneas ou como um inevitável destino, meta ou telos. (DALE, 2001, p. 134).

Boaventura de Souza Santos (2001) detecta dois grandes movimentos de globalização, os quais denomina de "globalização hegemônica", liderada pelas empresas transnacionais, pelos organismos financeiros internacionais e pelos capitalistas dos países centrais, e "globalização contrahegemônica", representada pelos movimentos sociais, ONGs progressistas e que vêm se articulando no Fórum Social Mundial. Esses movimentos ocorrem a partir das três principais contradições vistas por esse autor no período atual: entre o global e o local; entre o Estado-Nação e o não-estado transnacional; e entre os que vêem a globalização neoliberal como inexorável e os que apontam um caminho alternativo de caráter anticapitalista (SANTOS, 2001, p. 60 -61).

Além dessa constatação, Santos define quatro modos de produção da globalização: os localismos globalizados, os globalismos localizados, o cosmopolitismo e o patrimônio comum da humanidade, sendo que os dois primeiros correspondem ao padrão da globalização hegemônica, enquanto os dois últimos ao movimento da globalização contra-hegemônica.

Para Boaventura, a globalização de localismos faz-se a partir da capacidade de certas práticas criadas localmente serem impostas a outros locais, chegando mesmo o autor a perguntar se o que ocorre no mundo não seria mais corretamente chamado de americanização ou ocidentalização do que de globalização (SANTOS, 2001, p. 51). Essas mesmas práticas, ao serem 
localizadas em outros lugares que não o seu de origem, tornam-se globalismos localizados, e nesse sentido o outro lado da mesma moeda representa o lado fraco do sistema. Obviamente o autor não vê esse movimento nem como impermeável ou hermético, mas sim como dialético e, dessa forma, os localismos ao se globalizarem se alteram e são relocalizados a partir de estruturas históricas e culturais locais que geram algo novo, apesar de seu caráter global.

Por outro lado, a globalização contra hegemônica se faria por dois movimentos, segundo Santos (2001): o cosmopolitismo, típico de movimentos gerais de contestação à globalização hegemônica, e o patrimônio comum da humanidade, como elemento de preservação contra os globalismos. Ambos também não ocorrem de maneira translúcida ou sem contradições, até por se tratarem de caminhos alternativos e, dessa maneira, tatearem por encontrar a forma de contestação e de construção de uma nova hegemonia.

Essa interpretação multívoca e dialética do fenômeno da globalização leva a compreensões mais amplas do atual em que vivemos. Não cabe, portanto, uma resposta simplória de que nada mudou, que o capitalismo continua o mesmo do início do século XIX ou XX. Houve, efetivamente, uma "compressão, temporal e espacial, do mundo como um todo" (ROBERTSON, 2000, p. 12), que exige novas respostas, em nível local e também global. Ou seja, não basta a pergunta "o que mudou" nem uma resposta simplista que nada mudou, que se convive hoje com o mesmo capitalismo do século XX, tais como apregoam algumas correntes políticas e intelectuais, ou ao contrário uma resposta entusiástica de que as mudanças são de tal monta que nada mais se assemelha aos séculos anteriores.

Partimos aqui da idéia de que muita coisa mudou, de que não se vive mais sob o mesmo capitalismo do século XX. Porém, essas mudanças também não significam alterações nas relações entre setores sociais dominantes e dominados e entre lugares do mundo, países mais e menos privilegiados no sistema mundo. Mantém-se, desse ponto de vista, a existência de centro, semiperiferia e periferia no sistema mundo (WALLERSTEIN, 1990), assim como entre regiões dentro dos diferentes países e, principalmente, conservamse a distribuição da riqueza socialmente produzida de maneira profundamente desigual entre os diferentes segmentos sociais.

Nesse sentido, é preciso separar o que vem ocorrendo no campo das novas tecnologias e, portanto, com características reais, dos aspectos políticos e das opções de organização econômica, social e cultural, que vêm sendo tomadas pelas camadas dominantes, além das necessárias disputas entre diferentes projetos de sociedade e das diferenciadas formas de inserção dos setores sociais e regiões nessa pretensa "globalização". 


\section{A globalização como opção política frente a futuros abertos}

De fato, a globalização não é unívoca, ou seja, o movimento atual da economia, da política e da cultura levado a cabo pelos setores hoje dominantes é uma opção entre outras, entre as quais podemos detectar algumas de caráter contra-hegemônico, particularmente aquelas que se articulam em torno do Fórum Social Mundial. Fazer a análise desse fenômeno, buscando compreender o que são mudanças reais e o que são opções políticas tomadas entre diferentes futuros abertos, é um imperativo intelectual e político.

Desta feita, é possível dizer que a globalização, tal como vem sendo desenhada e implementada pelo neoliberalismo hegemônico, é uma, entre as variadas possibilidades abertas com as mudanças tecnológicas. É aquela orquestrada pelas empresas transnacionais e pelos governos dos países centrais, onde se localizam as matrizes organizações, com o objetivo de ampliar sua capacidade de lucro econômico-financeiro e de domínio político-ideológico.

Algumas condições possibilitaram o ataque ao estado providência (SANTOS, 1999), ao keynesianismo e ao fordismo antes aplicados nos países centrais e, de alguma forma, também nos semiperiféricos e ainda com influências claras até mesmo na periferia do sistema mundo (WALLENSTEIN, 1990).

Duas razões parecem ser as mais fortes na abertura da possibilidade desse ataque: uma econômica e a outra política. Essas razões surgiram com derrocada dos países do Leste, uma vez que "a queda do muro de Berlim fez derrubar a relação de forças e a reestruturação do modo de acumulação do capital" (HOUTART; POLET, 2002, p. 70), mesmo porque "é preciso lembrar que é a existência do bloco socialista, com suas ambigüidades que, ao menos indiretamente, impeliu as sociedades ocidentais a estabelecer os pactos sociais do pós-guerra" e, portanto, de parte do projeto socialista, alternativo ao capitalismo, que coloca a esquerda em crise, eliminando, dessa forma, o fantasma de uma alternativa ao capitalismo hegemônico. Nas palavras de Wallerstein (2000, p. 228):

Veio depois o choque da queda do comunismo. O recuo dos anos 70 e 80 virou fuga desordenada nos anos 90 . Grande parte dos esquerdistas de ontem viraram arautos do mercado e os que não seguiram esse caminho procuram ansiosamente por trilhas alternativas.

Esses fatores possibilitam uma arrancada em direção da ampliação do lucro e da hegemonia capitalista. Trata-se de nova fase de desenvolvimento das forças produtivas e suas respectivas adaptações às formações sociais e culturais. 
Por sua vez, a razão econômica é composta pela revolução tecnológica, que aproxima lugares, torna a comunicação imediata e os transportes menos dispendiosos e mais seguros, além de novas formas de organizar o trabalho, que ampliam ainda mais as possibilidades de lucros com as novas tecnologias.

A revolução tecnológica (SCHAFF, 1990) empreendida ao longo dos últimos 30 anos aumentou de maneira extraordinária a capacidade produtiva. A informática é, na visão de Schaff (1990), a revolução que passa às máquinas funções intelectuais que até então eram exercidas pelo ser humano. Esse autor chega mesmo a visualizar uma sociedade com um mínimo de trabalho na versão moderna do termo, em que a imensa maioria das funções mecânicas e mesmo intelectuais seriam efetivadas por máquinas. É preciso ainda que se some a esse desenvolvimento tecnológico a adoção em larga escala, pelas empresas, de novas formas de organizar o trabalho pós fordistas/tayloristas, ampliando ainda mais a capacidade produtiva (ANTUNES, 1995). Esse novo modelo, chamado por vários autores, como Adriano Sandri, de Toyotismo, tem como características importantes a flexibilidade de funções, a ausência de estoque, a extensa utilização de tecnologia da informática e da robótica, a participação dos trabalhadores e o dinamismo produtivo (SANDRI, 1994).

Tal Revolução não acontece apenas na produção, mas também, e principalmente, nas comunicações e nos transportes, que permitem que uma empresa tenha seu bureau de criação em uma zona do planeta e as áreas de produção em quaisquer outras zonas, pois todas podem estar interligadas com comunicação on-line. Além disso, graças também aos avanços tecnológicos, esses produtos podem ser levados e comercializados em qualquer parte. São ainda as novas tecnologias na área de comunicação que viabilizam as transações financeiras, que têm se expandido de maneira exorbitante, pelo mundo.

Essas novas forças econômicas, ao mesmo tempo em que liberam o capital para novas ofensivas, obrigam-no a isso, na medida em que as novas escalas de produção e o potencial de comércio viabilizado com as novas tecnologias do transporte e da comunicação fazem com que o capital tenha a necessidade de expandir seus tentáculos pelo mundo. Essa necessidade exige uma nova conformação política e, portanto, ideológica, diferente do que havia sido o projeto capitalista na segunda metade do século XX.

Durante a segunda metade do século XX, após o colapso capitalista de 1929 e as guerras, o capitalismo entra em nova fase, seja por suas necessidades intrínsecas ditadas pela possibilidade da acumulação, seja por razões políticas de manutenção do próprio capitalismo frente ao desenvolvimento econômico, 
àquela altura, da União Soviética, com taxas de crescimento econômico de mais de 10\% (MICKETHWAIT; WOLDRIDGE, 2000), seja pela força demonstrada pelo movimento sindical nos países centrais. Nunca é demais lembrar a força dos sindicatos alemães e italianos no início do século XX ou a capacidade de pressão dos sindicatos franceses e ingleses, que certamente obrigaram as classes dominantes locais a aceitar certos cortes nos lucros e impingiram ao Estado a necessidade de conter, com concessões, a ampliação dessa força.

As políticas de intervenção estatal na economia, que de alguma forma lembravam as medidas propostas por Keynes, e que por isso passaram a ser chamadas de keynesianismo, e a incorporação por parte do estado capitalista de obrigações para com as condições de vida de seus cidadãos, particularmente os trabalhadores, pois estes tinham maior poder de pressão por meio do movimento sindical e dos próprios partidos de esquerda, tornaram-se o modelo de organização capitalista.

Ainda que este sistema, conhecido como Estado Providência, tenha se desenvolvido e sido implantado, mesmo que de formas diferentes e variadas, apenas nos países do capitalismo central ele serviu como modelo a ser buscado nos países semiperiféricos e periféricos (SANTOS, 2001). É, nesse sentido, bastante ilustrativa a frase atribuída com freqüência ao ex-ministro Delfim Netto, responsabilizado pelo chamado milagre brasileiro na década de 70: "temos que esperar o bolo crescer para depois dividir". Tal frase sintetiza a própria visão periférica sobre o papel do estado: dividir, demonstrando claramente a aceitação dos cânones social-democratas, ainda que de maneira alguma esse modelo tenha se implantado na periferia do sistema. O modelo social democrata, assim, se universaliza como idéia, como modelo, mas não como efetividade, como realidade. Mesmo assim, ou seja, como modelo, tal concepção contém uma força incrível, seja na própria ação governamental, seja na organização popular em torno da idéia de cidadania tão imbricada com o próprio conceito de Estado Nacional e, portanto, com as obrigações de um estado típico capitalista.

Contra esse modelo de Estado Providência levanta-se um outro projeto político: o neoliberalismo. É o corolário político do desenvolvimento capitalista e da derrocada da União Soviética e seus aliados que, de alguma forma, serviam de freio aos ímpetos mais brutais do próprio capitalismo. O neoliberalismo surge como idéia já na construção da Social Democracia (ANDERSON, 1995). Ainda em 1944, F. Hayek lança o livro "Caminhos da Servidão" atacando as propostas do Partido Trabalhista inglês, então seu alvo preferencial, e o modelo soviético. Os ataques teóricos ao Estado Providência e às idéias socialistas continuam por parte de ultraliberais com Hayek e Milton 
Friedman, outra figura proeminente do neoliberalismo, e para tal constroem a Mont Pèlerin Society (LIMA; MARQUES; PEREIRA, 2002). Esses ataques teóricos passam a virar política de Estados na década de 80 e foram se tornando hegemônicos ao longo dos anos 90, a partir do Consenso de Washington.

A liberalização radical baseia-se no princípio de que o mercado é o melhor, senão o único, mecanismo de regulação das relações econômicas entre os indivíduos. Qualquer outra tentativa de organizar racionalmente os preços e salários contrapor-se-ia à liberdade dos indivíduos, cabendo, portanto, ao Estado apenas garantir o cumprimento das regras nesse jogo do mercado (LIMA; MARQUES; PEREIRA, 2002).

Com essa "fé" na capacidade de o mercado melhor realocar os recursos econômicos na sociedade e dada a necessidade do capital, nessa nova fase de desenvolvimento tecnológico, os dogmas do neoliberalismo vão sendo impostos pelas agências financiadoras internacionais - particularmente o Fundo Monetário Internacional (FMI) e o Banco Mundial -, aos países em geral, e aos Estados da periferia e da semiperiferia, em particular. Essa ideologia (STIGLITZ, 2002) foi sendo, assim, "recomendada" aos países que necessitassem da ajuda desses organismos. Mesmo nos países centrais, as possibilidades abertas com as novas condições tecnológicas levaram o capital a conquistar mudanças e acabar brutalmente com o Estado Providência, ampliando, dessa forma, sua capacidade de lucro.

O "pacote" do Consenso de Washington pode ser resumido, segundo Santos (2001, p. 35):

Nas seguintes exigências e orientações: as economias nacionais devem se abrir ao mercado mundial e os preços locais devem tendencialmente adequar-se aos preços internacionais; deve ser dada prioridade à economia de exportação; as políticas monetárias e fiscais devem ser orientadas para a redução da inflação e da dívida pública e para a vigilância sobre a balança de pagamentos; os direitos de propriedade devem ser claros e invioláveis; o setor empresarial do Estado deve ser privatizado; a tomada de decisão privada, apoiada por preços estáveis, deve ditar os padrões nacionais de especialização, a mobilidade dos recursos, dos investimentos e dos lucros; a regulação estatal da economia deve ser mínima; deve reduzir-se o peso das políticas sociais no orçamento do Estado, reduzindo o montante das transferências sociais, eliminando sua universalidade, e transformando-as em meras medidas compensatórias em relação aos estratos sociais equivocadamente vulnerabilizados pela atuação do mercado. 
Esse "evangelho da economia de mercado" (STIGLITZ, 2002, p. 180) transforma não apenas os mecanismos de orientação econômica como também as noções de justiça, direitos, solidariedade, enfim, cidadania, que são trocadas por noções como poder de compra, competitividade, enfim, consumidores. É a aplicação prática da pregação, feita em ambiente desfavorável por muito tempo, dos ultraliberais, como Hayek e Friedman.

A aplicação dessas políticas tem levado à ampliação da desigualdade social no mundo. As facilidades oferecidas às empresas transnacionais não se aplicam às pessoas, assim, "a dimensão global das opções dos investidores, quando comparada aos limites estritamente locais da opção do 'fornecedor de mão-deobra' garante essa assimetria, que por sua vez é subjacente à dominação dos primeiros sobre o segundo" (BAUMAN, 1999, p. 113).

A OMC (Organização Mundial do Comércio), bem como outros acordos e projetos multilaterais, como a ALCA, e as pressões econômicas pela adoção das medidas preconizadas por Washington podem ser claramente identificadas - por exemplo, na idéia do AMI (Acordo Multilateral de Investimentos) -, como a criação de legislação supranacional de enquadramento e garantias do capital indiferentemente do governo de cada estado nação.

À frente desse processo encontram-se dois dos seus principais protagonistas: o FMI (Fundo Monetário Internacional) e o Banco Mundial. Eles contaram com o enfraquecimento dos estados nacionais para garantirem a política de ampliação da capacidade de absorção de lucro pelas transnacionais, tendo como referência o modelo americano de judicialização (SANTOS, 2001).

Complementarmente a esse movimento do capital, vemos a transferência do poder de decisão dos estados para os organismos multilaterais e, portanto, dos cidadãos para os dirigentes desses organismos, em claro esvaziamento do poder seja do Estado-Nação, seja do cidadão desse estado. Nas palavras de Bauman (1999, p. 76): “A separação entre economia e política e a proteção da primeira contra a segunda, o que resulta na perda de poder da política como agente efetivo, auguram muito mais do que uma simples mudança na distribuição do poder social". Mesmo porque, "abrir de par em par os portões e abandonar qualquer idéia de política econômica autônoma é a condição preliminar, docilmente obedecida, para receber assistência econômica dos bancos mundiais e fundos monetários internacionais" (BAUMAN, 1999, p. 76).

Assim, os Estados-Nação vão, paralelamente ao fortalecimento das empresas transnacionais e dos organismos multilaterais, perdendo capacidade de gerar políticas econômicas autônomas. Alguns vão se tornando 
mesmo "quase estados, Estados fracos [que] podem ser facilmente reduzidos ao (útil) papel de distritos policiais locais que garantem o nível médio de ordem necessário para a realização de negócios, mas não precisam ser temidos como freios efetivos à liberdade das empresas globais" (BAUMAN, 1999, p. 76).

Eis, portanto, um esboço do contexto atual, no qual as classes subalternas sobrevivem. Nele é que elas deveriam atuar em busca da conquista de libertação econômica, sociopolítica e cultural, de forma a garantir melhores condições de trabalho e de vida. Contudo, esse processo de luta, já historicamente experienciado, encontra hoje novos desafios.

\section{A educação política e a luta contra-hegemônica}

Nesse contexto de hegemonia do capital, que se globaliza, há necessidade de desenvolver ainda mais a globalização contra-hegemônica, nos termos em que Boaventura de Sousa Santos a apresenta. Contudo, para que a globalização contra-hegemônica tenha sucesso, ela precisará dilatar aquilo que ela já produziu historicamente: a sua capacidade de enfrentar diferentes situações que lhe são desfavoráveis, de forma a superá-las em seu próprio benefício como classe.

As novas situações vividas no contexto mundial, que reverbera no local, fundam-se num novo padrão moderno ocidental de sociabilidade. $\mathrm{O}$ processo que cria esse padrão de relações econômicas, políticas e sociais é baseado na forma capitalista de apropriação da natureza e de relação entre os diferentes setores sociais. Sua característica elementar é a apropriação privada dos meios de produção por parte dos capitalistas, que também tomam posse do excedente socialmente produzido. Tal apropriação dá-se em detrimento de amplas parcelas da população cuja participação no produto social é, muitas vezes, insuficiente para sua própria sobrevivência.

Essa exploração econômica geradora de riqueza nas mãos de poucos pode, e em geral o faz, combinar-se com formas de opressão que ampliam ainda mais o potencial de exploração. De modo que se gera na sociedade, além de setores explorados, incluídos no processo de produção capitalista, setores oprimidos, que podem ou não estar inseridos nesse processo (SANTOS, 1999).

A conformação do modelo de funcionamento dos mecanismos sociais de inclusão e de exclusão foi denominada, a partir da própria produção teórica liberal do final do século XVIII, de contrato social. Para Santos, "o contrato social é a metáfora fundadora da racionalidade social e política da modernidade ocidental" (SANTOS, 2006, p. 318). 
A modernidade ocidental atual é o período em que tal contrato foi sendo estendido e ampliado. Estendido no sentido de que os setores que estavam excluídos vão sendo incluídos, por meio de lutas específicas que garantem concessões. Ampliado no sentido de que os setores incluídos no contrato de forma subalterna vão, também por meio de lutas, cooptações e concessões, ampliando seus direitos e, portanto, seu espaço no contrato social.

O contrato social, bem como as lutas e concessões que o vão alargando, constituem a cidadania, na sua concepção moderna, como condição dos seres humanos que desfrutam de direitos por participarem de determinada sociedade, organizada dentro do Estado Moderno, supostamente nacional. Tal idéia, oriunda em sua gênese do período clássico, adquire novas conotações no período moderno, sendo alvo de disputa e de combates por parte dos excluídos desses direitos. Ao longo dos séculos XIX e XX, diversos setores sociais vão forçando sua entrada no contrato social, reivindicando direitos, tais como as mulheres, minorias étnicas, imigrantes, portadores de deficiência e pessoas com distintas orientações sexuais.

A manutenção da capacidade de domínio das classes dominantes sobre o conjunto da sociedade, particularmente sobre os setores explorados e oprimidos, constitui-se num dos principais objetos de estudo e teorização por parte dos críticos do sistema capitalista. O debate e a produção teórica acerca dos instrumentos e formas utilizados pelas classes dominantes no sentido de manter seu domínio tem, assim, ocupado extenso número de páginas da produção crítica, particularmente da produção de matriz marxista.

É importante lembrar que a manutenção das estruturas de exploração e de opressão não se dá, obviamente, sem conflitos. A própria estruturação do contrato social acontece no conflito entre as forças denominadas por Boaventura de Sousa Santos de emancipatórias e regulatórias (SANTOS, 1999). As forças emancipatórias são aquelas que atuam no sentido da ampliação e extensão do contrato social, ao passo que as forças regulatórias atuam no sentido da manutenção dos limites de tal contrato, tendo em vista a permanência das estruturas de exploração e de opressão. As forças da regulação cederam ao longo da modernidade às forças da emancipação, gerando contratos sociais cada vez mais amplos e abrangentes, particularmente nos países centrais do capitalismo ocidental. O maior exemplo dessa extensão e abrangência é o Estado Providência dos países do norte da Europa, como a Suécia, a Dinamarca e a Noruega.

O conceito de emancipação utilizado por Boaventura de Sousa Santos traz enorme contribuição ao debate sobre a necessidade de superação do capitalismo, na medida em que aponta para uma maior inclusão social, sem, no entanto, vincular-se a uma forma específica dessa maior inclusão e sem ser, assim, 
teleológica. Trata-se de um conceito que incorpora a possibilidade de transformação social, mas como possibilidade, ou seja, não como determinismo histórico. A emancipação é, dessa forma, uma das forças que age na realidade, na tensão com a regulação, buscando ampliá-la. Está vinculado à idéia de dignidade humana, não estabelecendo uma forma ou uma direção específica na conquista de tal condição. Pretende, assim, este conceito poder ser traduzido para outras culturas e formas de ver e compreender o mundo (SANTOS, 1995, 1999, 2001).

Assim, para Boaventura, a disputa pela hegemonia acontece exatamente no senso comum, hoje impregnado da visão de mundo dominante, e que pode, e deve, ser tensionado pelo pensamento emancipatório e sua visão de mundo. Esse "convencimento", que no nosso modo de ver guarda relação com a formulação gramsciana, não se dá simplesmente pelo discurso teórico, mas também, e fundamentalmente, pela práxis, pela construção de alternativas críveis, ainda que localizadas, com "vocação hegemônica". Ainda que localizadas, essas experiências podem apontar pistas com perspectiva de escala global.

Aplicando a "Sociologia das Ausências", uma postura científica engajada, pretende Santos tornar presentes experiências tornadas ausentes pelas forças hegemônicas, sendo que "tornar-se presentes significa ser consideradas alternativas às experiências hegemônicas, a sua credibilidade poder ser discutida e argumentada e suas relações com as experiências hegemônicas poderem ser objeto de disputa política" (SANTOS, 2002a, p. 249). Portanto "objetivo da sociologia das ausências [ é o de] revelar a diversidade e multiplicidade das práticas sociais e credibilizar esse conjunto em contraposição à credibilidade exclusiva das práticas hegemônicas" (SANTOS, 2002a, p. 253).

Santos destaca ainda o papel dos intelectuais, que adjetiva como "cosmopolitas" (SANTOS, 2002b), a quem caberia formulação de um novo senso comum, emancipatório. Nesse sentido, caberia a eles um papel destacado no trabalho de tradução, considerando como fundamental a tradução entre os diferentes movimentos sociais, de diferentes práticas culturais.

A aplicação de tais conceitos no mundo contemporâneo tem ainda um complicador. O período de construção da hegemonia neoliberal é um momento em que as forças da regulação estão conseguindo reduzir os termos do contrato social, excluindo e diminuindo a amplitude dos direitos dos cidadãos e cidadãs. Mais importante ainda torna-se desenvolver tais idéias e aplicá-las ao mundo contemporâneo, no sentido de compreendê-lo para transformá-lo, cumprindo assim o papel da ciência como conhecimento entre outros, em diálogo para construir um futuro mais decente. 
Diferentemente, portanto, de todo o período anterior da modernidade, o presente apresenta-se como momento da retração da regulação social, do rebaixamento das expectativas em relação à experiência. É essa nova hegemonia neoliberal que se coloca na atualidade.

Vê-se, portanto, que para Boaventura de Sousa Santos, a transformação ocorre a partir de intervenções na sociedade civil. O desafio que se apresenta é articular a luta local de forma a que ela seja capaz de desvelar as relações sociais aí presentes e, assim, formar sujeitos aptos à disputa pela hegemonia com as classes dominantes e dirigentes.

\section{Referências}

ANTUNES, R. Adeus ao trabalho? Ensaio sobre as metamorfoses e a centralidade do mundo do trabalho. Campinas, SP: UNICAMP, 1995.

ANDERSON, P. Balanço do neoliberalismo. In: SADER, Eder; GENTILI, Pablo (Org.). Pós-Neoliberalismo: as políticas sociais e o estado democrático. 4. ed. São Paulo: Paz e Terra, 1995. p. 205-207.

BANCO MUNDIAL. Globalização: crescimento e pobreza. São Paulo: Futura, 2003.

BAUMAN, Z. Globalização: as consequiências humanas. Rio de Janeiro: Jorge Zahar, 1999.

DALE, R.; ROBERTSON, S. The varying effects of regional organizations as subject of globalization on education. Comparative Education Rewiew, Londres, v. 46, n. 1, p. 10-36. Fev. 2001.

HOUTART, F; POLET, F. (Org.). O outro Davos: mundialização de resistências e de lutas. Tradução Mariclara Oliveira. São Paulo: Cortez, 2002.

LIMA, T.; MARQUES, C.; PEREIRA, E. T. Friedrich August Von Hayek (1899-1992): da liberdade à educação. Revista da Educação, Valinhos, v. 5, n. 5 , out. 2002.

MICKETHWAIT, J.; WOLDRIDGE, A. O futuro perfeito: os desafios e armadilhas da globalização. Tradução de Afonso Celso da Cunha Serra. Rio de Janeiro: Campus, 2000. 
ROBERTSON, R. Globalização: teoria social e cultura global. Petrópolis, RJ: Vozes, 2000.

SANTOS, B. S. A transição paradigmática: da regulação à emancipação. Oficina do CES, Coimbra-Portugal, n. 25, 1995.

A construção multicultural da igualdade e da diferença. Oficina do CES, Coimbra-Portugal, n.135, jan. 1999.

Os processos da globalização. In: SANTOS, B. S. (Org.). Globalização: fatalidade ou Utopia. Porto: Afrontamento, 2001.

Um discurso sobre as ciências. 13. ed. Porto: Afrontamento, 2002a. Para uma sociologia das ausências e uma sociologia das emergências. Revista Crítica de Ciências Sociais, Coimbra-Portugal, n. 63, CES, out. 2002 b.

A gramática do tempo: para uma nova cultura política. São Paulo: Cortez, 2006.

SANDRI, A. Sindicalismo em tempos de qualidade total. Belo Horizonte: Sindeletro, 1994.

SCHAFF, A. A sociedade informática. São Paulo: UNESP; Brasiliense, 1990.

STIGLITZ, J. E. Globalização: a grande desilusão. Lisboa: Terramar, 2002.

WALLERSTEIN, I. O sistema mundial moderno. Porto: Afrontamento, 1990. v. 1. 